\title{
Identifying Barriers and Enablers for Climate Change Adaptation of Farmers in Semi-Arid North-Western China
}

\author{
Lan $\mathrm{Mu}$ *, Lan Fang, Yuhong Liu and Chencheng Wang \\ Northwest Institute of Historical Environment and Socio-Economic Development, Shaanxi Normal University, \\ $\mathrm{Xi}^{\prime}$ an 710062, China; fanglan@snnu.edu.cn (L.F.); liuyuhong8023@snnu.edu.cn (Y.L.); \\ wangchencheng123@snnu.edu.cn (C.W.) \\ * Correspondence: mulan820706@snnu.edu.cn; Tel.: +86-29-8531-8752; Fax: +86-29-8531-8753
}

Received: 17 August 2020; Accepted: 9 September 2020; Published: 11 September 2020

\begin{abstract}
The changing climate represents a large challenge for farmers, and adaptation responses are necessary to minimize impacts. Mixed approaches, which involve the analysis of meteorological data, web-based surveys, and face-to-face interviews, explore producers' barriers and pressing needs to enhance climate resilience based on the Technique for Order Preference by Similarity to Ideal Solution (TOPSIS) approach in semi-arid north-western China. According to the main categories of farming activity, 85 crop farmers, 68 animal farmers, and 81 agro-tourism operators were interviewed. We found that most of the producers perceived climate impacts, and they encountered multiple adaptation obstacles, of which institutional and normative obstacles were more serious, such as farmers unable to obtain resources or government incentives, lacked scientific, and efficient coping measures. The survey also observed that crop farmers had a pressing need for agricultural subsidies, while animal farmers and agro-tourism operators had a strong enabler for animal housing infrastructure and credit facilities, respectively. Given the heterogeneity of the context and climate change experience of different categories of farmers, it is necessary to formulate flexible adaptation strategies and adjust them according to specific climate stress and farming conditions. To achieve the Sustainable Development Goals and implement the 2015 Paris Agreement, policymakers should plan and introduce appropriate adaptation strategies to minimize the adverse effects of climate change such as improving irrigation and weather forecasting system through technological advancement, cost reduction of farm inputs, ensuring availability of information, providing agricultural subsidies to the farmers, and increasing the access to agricultural markets.
\end{abstract}

Keywords: climate change; barriers; enablers; adaptation strategies; semi-arid north-western China

\section{Introduction}

Climate change is considered to be one of the most complex social and economic challenges facing the world. The effects of these changes in climatic conditions vary across the world, the most serious of which are observed in developing countries due to a combination of numerous factors, such as a lack of basic resources, poor economic conditions, and a lack of awareness regarding effective adaptive measures $[1,2]$. Disadvantages and poverty have been exacerbated by recent climate warming, and as the global average temperature rises by $1{ }^{\circ} \mathrm{C}$ to $1.5^{\circ} \mathrm{C}$ or even more, it is expected that the poverty and disadvantage of many populations will increase [3]. Because the major cause of climate change is greenhouse gas emissions (GHG), the path to climate mitigation is the best and rapid reduction in total GHG. The largest contributors of anthropogenic GHG emissions worldwide are GHG-intensive firms from the energy and industry sectors [4-8]. However, agriculture is considered one of the sectors most 
vulnerable to the adverse effects of climate change, including loss of biodiversity, water accessibility loss, crop failure, pest pressure, and disease $[9,10]$. Smallholder farmers in developing countries, such as China, are more vulnerable to the negative effects of climate change than are those in developed countries because they are heavily dependent on natural resources and agriculture [11]. It is projected that this change will intensify in the coming decades, further increasing the vulnerability of poor farmers and adversely influencing food security and agriculture production [12]. Therefore, the current stagnation requires farmers to be aware of climate change and adopt adaptation strategies to minimize the stress to agricultural systems and to address potential loss of benefits [13]. Adaptation refers to the adjustments of practices, processes, and systems of land use and technology implementation to enhance resilience or reduce vulnerability to the changing climate and to maximize benefits by utilizing existing opportunities [14]. To adopt appropriate adaptation actions and technologies, nevertheless, the ability of farmers to recognize climate change is an essential prerequisite to adaptation [15]. Awareness towards climate change means farmers must be aware of climate change vulnerability, which may vary among different regions due to differences in national, political, and cultural backgrounds. It has been emphasized that producers will adapt only when they expect to benefit from the practices of adaptation [16]. Before adopting measures, farmers think about the estimated benefits and costs of specific adaptive actions and implement corresponding practices if the revenue exceeds the cost [17]. Some researchers have investigated how Chinese farmers respond to climate change $[18,19]$. However, there are few reports on the status quo of rural communities and semi-arid areas in northwest China, and there is little understanding of producers' recognition of climate change and adaptive measures being used. Therefore, it is increasingly necessary to establish a policy framework to address climate change in this region, determine the background of climate change vulnerability, identify obstacles, and formulate corresponding adaptation strategies.

Climate adaptation is a long-term, complicated, and systematic response process, and farmers are often influenced by many obstacles, which may restrict the process of adaptation. These barriers are constraints to the changing climate because of the lack of understanding of climate change issues, inadequate technical knowhow, insufficient funding, and institutional capacity, which is largely divided into four principle categories: Cognitive barriers, normative barriers, information and technology barriers, and institutional barriers [20]. Cognitive obstacles are related to psychological procedures that affect individuals' responses to climate stimuli, such as indifference, denial, powerlessness, and perception basis [21]. Normative barriers refer to inappropriate adaptation manners that are influenced by religious beliefs and traditional culture, such as reluctance to improve inefficient cultivation methods, as well as unwillingness to adopt preventive action in advance [22]. Information and technology obstacles signify the untimeliness and inaccuracy of the weather information obtained by farmers and inaccessibility to farming technology services (Boyd et al., 2013). Institutional obstacles refer to unsound regulations and laws, which are due to insufficient policy implementation, inadequate publicity and guidance, and lack of sophisticated capture resources in the process of climate adaptation [23]. All of these barriers are helpful for exploring the gap between broad cognition enablers for adaptation and generally insufficient actions.

The existence of these different obstacles not only prevents the farmers' ability to manage and identify climate change, but also increases adaptation costs, reduces adaptation efficiency, and restrains the implementation of adaptation policies [24]. Understanding the obstacles will contribute to better strengthening and sustainable agricultural to minimize the adverse effects of a changing climate on the national economy. Adaptation enablers are an important way to effectively reduce or eliminate obstacles and improve farmers' adaptive capacity to climate change. For the purpose of our research, we defined adaptation enablers as factors and conditions that stimulate collective abilities and efforts to adapt to current and future climate change such as weather information, credit support, and government incentives and so on [22]. Although previous research indicated that adaptation needs can be somewhat reduced through the provision of infrastructure, technology, credit, and agricultural insurances, adaptation obstacles and needs differ primarily in socioeconomic and 
cultural characteristics, regional systems, and specific geographical locations [21]. However, most producers, particularly in developing nations, have limited ability and understanding of these barriers to adapt to climate change [25]. Therefore, although different types of producers encounter adverse climatic events and take appropriate actions in most cases, most are not prepared to meet the challenge of increasingly frequent extreme weather events brought about by climate change [26]. Moreover, in semi-arid north western China, there is evidence that the increase of long-term drought, the increase of temperature and the decrease of precipitation have a significant impact on this area. Therefore, it is particularly urgent and necessary to identify the factors that cause obstacles and the needs of different categories of farmers in the region to improve adaptation strategies and adaptation capacity.

Thus, in this context, the objectives of this study are to (1) bridge the attitudes of climate change and its impacts on a diverse group of local farmers (crop farmers, animal farmers, and agro-tourism operators); (2) to identify the barriers and enablers of different categories of farmers to support the formulation of scientific adaptation practices, and (3) to explore proposed incentives and motivation to increase farmers' adaptability to a changing climate. The results will help developing countries to formulate appropriate adaptation policies and eliminate poverty in climate- and environment-sensitive regions. Additionally, the research provides practical evidence for studies on the adaptation of worldwide climate change to achieve the UN's Sustainable Development Goal for "Climate Action" [27].

\section{Research Methodology}

The method for exploring farmers' barriers and enablers in the study area was divided into three phases. First, interviews were conducted among crop farmers, animal farmers, and agro-tourism farmers in the area. Second, barriers indexes were established and quantified. Third, an integrated assessment approach based on TOPSIS was established to assess the severity of the barriers that farmers encountered of the study area.

\subsection{Study Site Description and Long-Term Climate Trend}

The study was conducted in Shaanxi Province, located in north-western China within the latitudes $31^{\circ} 42^{\prime}$ to $39^{\circ} 35^{\prime} \mathrm{N}$ and longitudes $105^{\circ} 29^{\prime}$ to $111^{\circ} 15^{\prime} \mathrm{E}$ (Figure 1), which is a typical semi-arid area with extreme weather, wind, and growing seasons dominated by a semi-arid continental monsoon climate. According to the Statistics Bureau, the region covers an area of $205,800 \mathrm{~km}^{2}$ and has 10 cities. The total population of the area is 38.12 million, of whom approximately $62.77 \%$ are settled down in rural areas. This region is a typical sensitive region to the worldwide changing climate with complex topography and geological structure. This area is known for its agricultural culture and plays a critical role in the national and global ecological structure. The agriculture is diversified, and the cultivated products are crop food crops (such as wheat, maize, rice), cash plants (such as fruits, vegetables, and legumes), and various kinds of horticultural products. In addition, farmers raise cattle, hogs, sheep, and goats. Despite the significance of cropland to regional food security and local farming production, the area's most productive and versatile cropland is at risk of transformation due to urban expansion into the countryside, and all specifically applied land use regulations attempt to maintain the farming production of land and mitigate the adverse effects of climate change. Although limited by land use scarcity and strict land-use regulations, farmers rely on a range of traditional short-term adaptation techniques to withstand challenging climatic conditions in the area. Examples included pruning that reduces water demand, canopy management to control sun exposure and resulting fruit damage, planting varieties that are better suited to the new climate conditions, practicing crop rotation to control pests, etc. Agricultural marketing channels in this area tend to be highly concentrated, which can be decisive in the farmers' adaptation strategies. Most crop production is either processed or marketed to domestic and foreign retailers directly by large producers, or adopted e-commerce tools to provide a means to sell their products through their online networks, and expanding those networks to expand their local markets. 


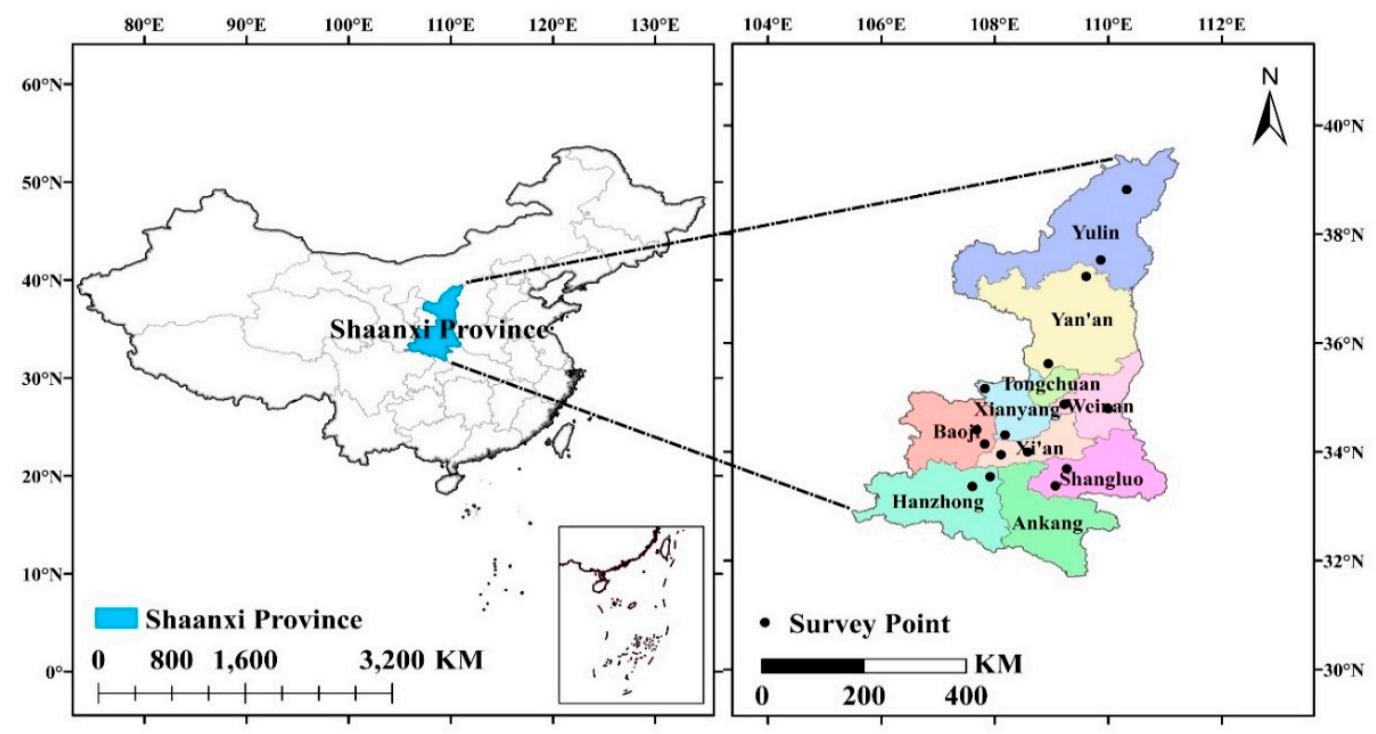

Figure 1. Map of the study area and the survey sites.

Agriculture is exposed to extreme climate change under global warming in this semi-arid area. As seen from Figure 2a, the average annual temperature in the study area showed an upward trend from 1951 to 2018, and the hottest years occurred in the past two decades. As reported by the National Climate Centre of China [28], the temperature will increase up to $+2.1-3.2{ }^{\circ} \mathrm{C}$, and rainfall will decrease $2 \mathrm{~mm}$ by the 2050s in the study area. According to the climate records in Figure 2b, there was a long-term declining trend for annual average rainfall in the last 60 decades, and the annual number was slightly below or along the mean of the investigated period. The climate change in the area has already seriously threatened the livelihood and production of local farmers. Thus, it is urgently important to develop scientific agricultural adaptation strategies and practices to improve adaptability, enhance resilience, and reduce vulnerability to the changing environment.

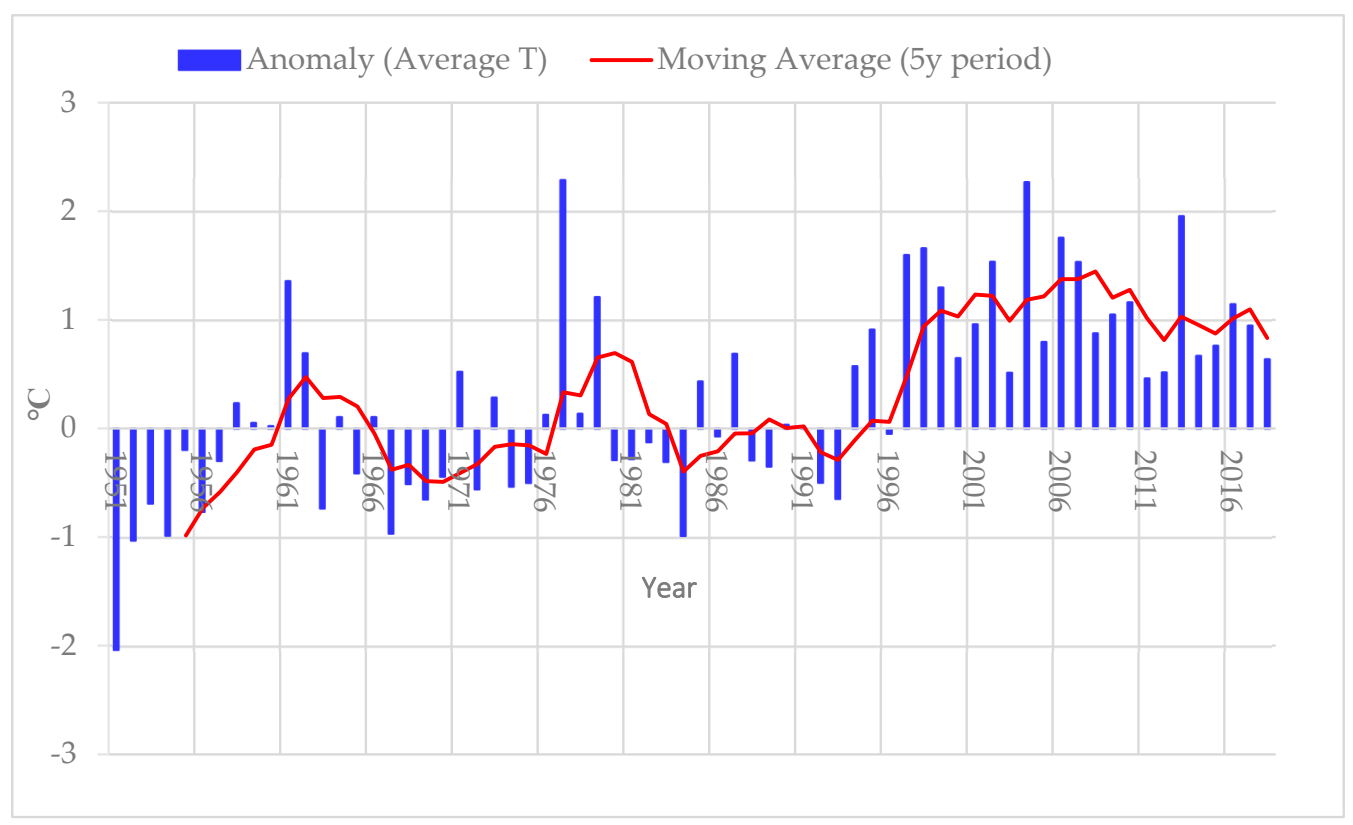

(a)

Figure 2. Cont. 


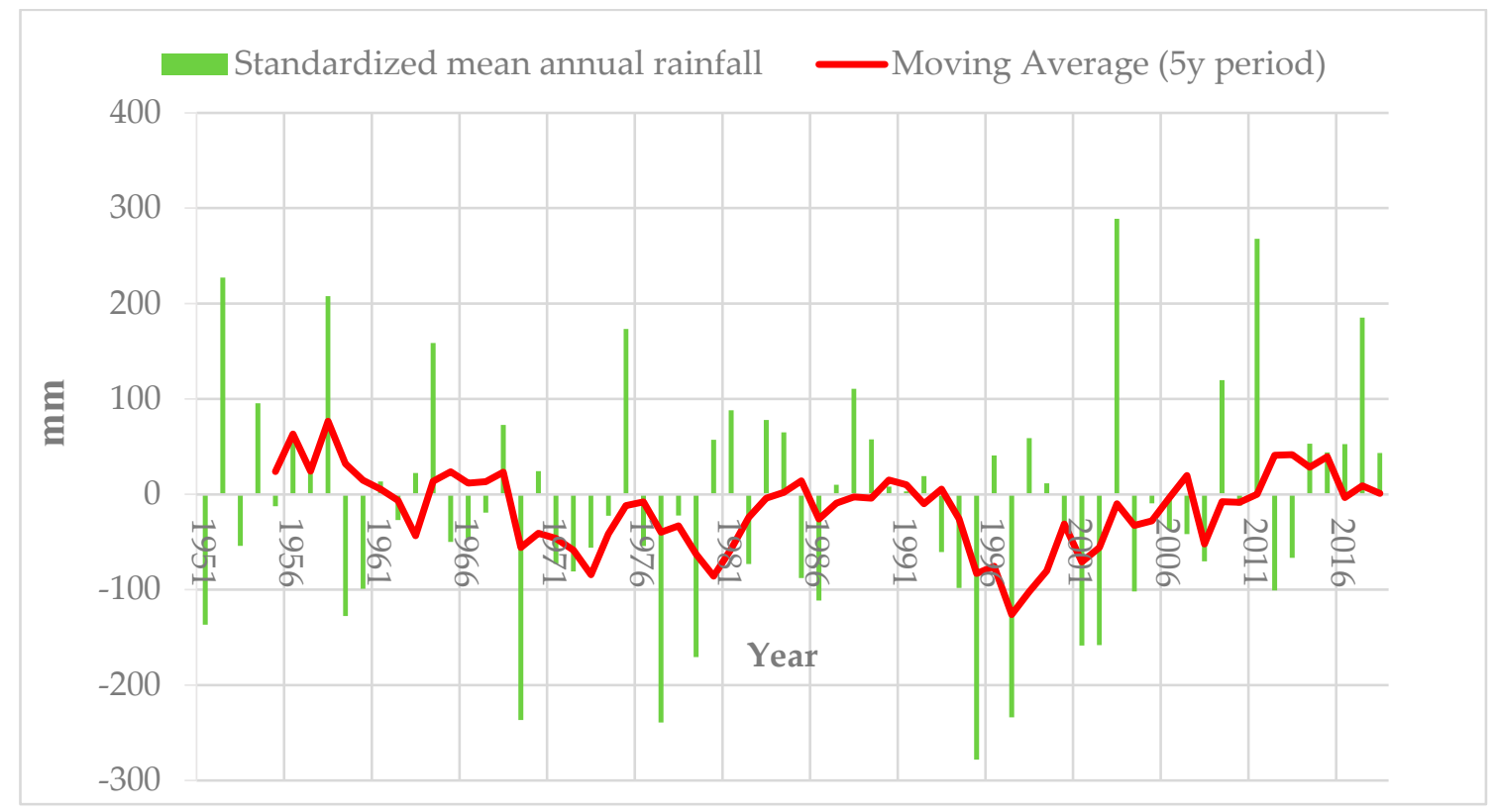

(b)

Figure 2. (a) Annual mean temperature anomaly in Shaanxi (1951-2018). Data source from Shaanxi weather station. (b) Standardized mean annual rainfall anomaly in Shaanxi (1951-2018). Data source from Shaanxi weather station.

\subsection{Survey Design and Data Collection}

To achieve the aim of the study, an inductive method according to survey data with face-to-face interviews asking relevant questions about climate change perception, barriers, and enablers for adaptation. In total, 68 face-to-face interviews were conducted in October 2019 and early January 2020. In addition, another 166 online or telephone-based interviews were done in March and April 2020 due to COVID-19. The interviews were deployed to 16 different counties selected with the use of a simple random sampling method, and 15 households were randomly selected from each target counties (Figure 1). According to the dominant agricultural operation behaviors of producers in the area, the interviewees were divided into three types: Crop farmers, animal farmers, and agro-tourism operators. Giving the characteristic of agriculture in these counties, there was more crop farming than livestock farming, therefore, 4 animal farmers, 5 agro-tourism farmers, and 6 crop farmers were randomly selected in each county. In total, 68 animal farmers, 85 crop farmers, and 81 agro-tourism operators were included in our research. The interviewed farmers' characteristics were summarized in Table 1. The interviews took approximately 40-120 min to be completed. All questions were open-ended, allowing for a discussion with the interviewees and avoiding leading of researchers in the discussion. To adopt appropriate measures to eliminate adaptation obstacles, the attitudes of producers to climate change were indispensable, and useful investigations should be conducted from the views of producers. Therefore, the interviews to the farmers aimed to collect general information including different types of farmers' cognition regarding climate change, the categories of climate effects they had already suffered, and the barriers and enablers that exist for adaptation practices.

\section{Farmers' attitude regarding climate change}

Within this section, the aim was to explore different categories of farmers' attitude (temperature and rainfall change) and knowledge of climate change and effects of the changing climate on agricultural disasters. Then, we explored whether farmers' cognition of climate change was in line with the observed weather data in the region. Moreover, when asking about the changes related to agricultural disasters, the disaster level was evaluated (not severe, severe, and very severe). 


\section{Barriers and needs for adaptation}

As shown in Table 2, we divided the barriers into four dimensions (institutional, information and technology, cognitive, and normative) and developed a comprehensive evaluation index system to evaluate adaptation obstacles. Additionally, the farmers were asked where they most needed help to adapt to the changing climate, which provides valuable information for other provinces and elsewhere.

\subsection{Method of Barrier Index $\left(B_{i}\right)$ Calculation}

According to relevant studies [29-32] and regional uniqueness, an integrated evaluation index system of adaptation obstacles was constructed, and four main categories of adaptation obstacles were determined. To more accurately judge and compare the severity and differences of the diversified barriers among different types of farmers from a quantitative perspective, the Technique for Order Preference by Similarity to Ideal Solution (TOPSIS) approach was applied in our research, and the final step of the previous method was improved to present the barrier index more explicitly [33,34]. The greater the value of the barrier index, the more serious the barrier encountered by farmers. The approach takes advantage of attribute information to carry out cardinality ordering of alternative schemes and attempts to seek the farthest distance (the answer with the greatest deviation from the objective reality) and the nearest distance (the answer closet to the objective reality) from the best answer [35]. For example, to assess perception barriers, if the observed rainfall data decreased in the last two decades, there is no perceptive bias for producers who recognize a reduction of rainfall, namely, there is no perceptive obstacle. In contrast, if producers recognized that the precipitation increased or was stable, they had perception obstacles, particularly those who recognized that a rainfall increase faces the most perception basis due to deviation of awareness from the observed precipitation trends. The information and technology, normative, and institutional barriers were ranked using the same approach. The degree of every barrier indicator was constructed in Table 2. The TOPSIS approach can be summarized in the following steps. 
Table 1. Characteristics of the interviewed farmers in the study area.

\begin{tabular}{|c|c|c|c|c|}
\hline Variable & Crop Farmers $(\mathrm{N}=85)$ & Animal Farmers $(\mathrm{N}=68)$ & Agro-Tourism Farmers $(\mathrm{N}=81)$ & All Farmers $(N=234)$ \\
\hline Average age (years) & 44.2 & 47.55 & 39.68 & 43.81 \\
\hline \multirow[t]{2}{*}{ Gender $(\%)$} & Male (46.3)/Female (53.7) & Male (68.2)/Female (31.8) & Male (47.7)/Female (52.3) & Male (54.1)/Female (45.9) \\
\hline & Junior high school or below (66.4) & Junior high school or below (71.5) & Junior high school or below (60.4) & Junior high school or below (66.1) \\
\hline \multirow[t]{2}{*}{ Education Background (\%) } & Senior high school (23.7)) & Senior high school (11.3) & Senior high school (23.1)) & Senior high school (19.4) \\
\hline & Bachelor or higher (9.9) & Bachelor or higher (8.2) & Bachelor or higher (16.5) & Bachelor or higher (11.5) \\
\hline Household labor force (persons) & 2.5 & 3.8 & 3.4 & 3.2 \\
\hline Years of farming (years) & 21.4 & 26.7 & 17.9 & 22 \\
\hline $\begin{array}{l}\text { Gross income per capital } \\
\text { (USD/years) }\end{array}$ & 1202.6 & 1678.4 & 1456.1 & 1445.7 \\
\hline
\end{tabular}

Table 2. Definitions of indicators for four dimensions of adaptation barriers (Perception, information and technology, normative, and institutional barriers) and summary statistics, $\mathrm{N}=234$.

\begin{tabular}{lll}
\hline Dimensions of Barriers & Adaptation Barriers & Coded Scoring \\
\cline { 2 - 3 } & Indicators Description & $\begin{array}{l}\text { Mean } \\
\text { (St.Dev) }\end{array}$ \\
\hline Perception barriers & Perception of drought frequency in the last few years & $1=$ increased, $0.5=$ stable, $0.0=$ decreased \\
\hline & Perception of new pest in the last few years & 0.626 \\
& Perception of extreme event in the last few years & $1=$ increased, $0.5=$ stable, $0.0=$ decreased \\
\hline
\end{tabular}


Table 2. Cont

\begin{tabular}{|c|c|c|c|}
\hline \multirow{2}{*}{ Dimensions of Barriers } & \multicolumn{3}{|l|}{ Adaptation Barriers } \\
\hline & Indicators Description & Coded Scoring & $\begin{array}{l}\text { Mean } \\
\text { (St.Dev) }\end{array}$ \\
\hline \multirow[t]{3}{*}{ Information and technology barriers } & Access to technical support & $1=$ accessibility, $0.0=$ inaccessibility & $\begin{array}{l}0.513 \\
(0.501)\end{array}$ \\
\hline & Timeliness of information acquisition & $\begin{array}{l}1=\text { highly timely, } 0.75=\text { mostly timely, } 0.25=\text { mostly not timely } \\
0=\text { highly not timely }\end{array}$ & $\begin{array}{l}0.474 \\
(0.428)\end{array}$ \\
\hline & Accuracy of information acquisition & $\begin{array}{l}1=\text { highly accurate, } 0.75=\text { mostly accurate, } 0.25=\text { mostly } \\
\text { inaccurate, } 0.0=\text { highly inaccurate }\end{array}$ & $\begin{array}{l}0.452 \\
(0.417)\end{array}$ \\
\hline \multirow[t]{2}{*}{ Normative barriers } & Manner of adaptation & $\begin{array}{l}1=\text { scientific and efficient manner } \\
0.0=\text { traditional and inefficient manner }\end{array}$ & $\begin{array}{l}0.419 \\
(0.494)\end{array}$ \\
\hline & Rationality of adaptation opportunity & $\begin{array}{l}1=\text { pre-disaster response, } \text { prevention } \\
0.0=\text { post-disaster response, remedy }\end{array}$ & $\begin{array}{l}0.380 \\
(0.487)\end{array}$ \\
\hline \multirow[t]{2}{*}{ Institutional barriers } & Availability of resources or assets & $1=$ obtain resources, $0.0=$ unable to obtain resources & $\begin{array}{l}0.303 \\
(0.401)\end{array}$ \\
\hline & Access to government incentives & $1=$ accessibility $0=$ inaccessibility & $\begin{array}{l}0.274 \\
(0.447)\end{array}$ \\
\hline
\end{tabular}


Step 1 Establish the original evaluation matrix:

Based on the first-hand data, $\mathrm{m}$ denoted the number of evaluation objects (including four main categories of barriers as shown in Table 2: Perception barriers, information and technology barriers, normative barriers, and institutional barriers), and $\mathrm{n}$ denoted the number of indexes for the evaluated barriers (i.e., three indexes were selected to characterize perception barriers, which were perception of drought frequency, new pests, and extreme events in the last few years). The performance matrix can be expressed as Equation (1) [32]:

$$
z_{i j}=\left[\begin{array}{cccc}
x_{11} & x_{12} & \ldots & x_{1 n} \\
x_{21} & x_{22} & \ldots & x_{2 n} \\
\vdots & \vdots \\
x_{m 1} & x_{m 2} & \ldots & x_{m n}
\end{array}\right]
$$

where $z_{i j}$ denotes the $j$ th evaluation index of the $i$ th evaluation object.

Step 2 Establish normalized matrix $\mathrm{Z}$ as Equation (2):

$$
\mathrm{Z}=\left\{z_{i j}\right\}_{m \times n} i=1,2, \ldots, m ; j=1,2, \ldots, n
$$

Step 3 Measure the distance from each alternative to the negative idea solution and the positive ideal solution as Equations (3) and (4):

$$
\begin{aligned}
& D_{i}^{+}=\sqrt{\sum_{j=1}^{n}\left(Z_{i j}-Z_{j}^{+}\right)^{2}} i=1, \ldots m \\
& D_{i}^{-}=\sqrt{\sum_{j=1}^{n}\left(Z_{i j}-Z_{j}^{-}\right)^{2}} i=1, \ldots m
\end{aligned}
$$

where $D_{i}^{+}$means the distance between the positive ideal solution and the $i$ th alternative, while $D_{i}^{-}$represents the distance between the negative ideal solution and the $i$ th alternative. Where $z_{j}^{+}=\max \left(z_{i j}, i=1,2 \ldots, m\right)$ and $z_{j}^{-}=\min \left(z_{i j}, i=1,2 \ldots, m\right)$.

Step 4 Calculate the relative closeness to the ideal solution as Equation (5):

$$
C_{i}=\frac{D_{i}^{-}}{D_{i}^{+}+D_{i}^{-}}
$$

where $C_{i}$ belongs to $[0,1]$, the case with $C_{i}$ closest to 1 , which is the target case

Step 5 Calculate the barrier index $\left(B_{i}\right)$ as Equation (6):

$$
B_{i}=1-C_{i}
$$

where $B_{i}$ belongs to $[0,1]$, being the case with $B_{i}$ closest to 0 , which means the lowest obstacles to adaptation faced by the producers.

\subsection{Data Analysis}

SPSS 25.0 (IBM, Armonk, NY, USA) software was used for non-parametric tests of multiple independent samples to identify statistically significant differences in adaptation obstacles and needs 
among the three categories of producers. We performed a descriptive analysis by percentages and frequencies of responses to circulate the principal adaptation obstacles and needs encountered by producers.

\section{Results}

\subsection{Attitudes and Agricultural Disasters Related to Climate Change}

In this research, climate change was defined as perceptive changes in the mean precipitation and temperature in the last several years. During the interviews, the recent increasing patterns in temperatures in the region were noted as a trend by $61 \%$ of the respondents, which was consistent with the long-term meteorological observation shown in Figure 2a. In contrast, the observed patterns of decreased rainfall in Figure $2 b$ were more significantly correctly recognized as undergoing change. Almost $85 \%$ of the interviewed producers complained that in the last few years the rainfall was decreased, and there was little rain when they were badly in need of it, but there was more when they did not need it, and the rainy time did not begin during the right season.

With respect to climate agricultural disasters, findings from the surveys were compiled according to three identified types of farmers, which are shown in Figure 3. For crop farmers (Figure 3a), the results showed that almost $76.5 \%$ of the farmers recalled that both planting and harvesting dates of crops changed with changing context, and the entire growing season was extended in the last several years. The changing climate also decreased the crop yield, which was confirmed by almost $61.0 \%$ of the producers during the interviews. Notably, $50.5 \%$ of the respondents stated that their income was decreased, while $33.4 \%$ held the opposite opinion. In addition, $68.6 \%$ of the participants ranked farmer income as the first most severe disaster in the study region followed by growing season, crop yield, and crop system. When asked the disaster level ranking among the crop farmers, 59.3\% of whom rated the length of growing season was the most severe disaster the encountered. Regarding animal farmers (Figure $3 \mathrm{~b}$ ), the results suggested that $66.4 \%$ of the farmers believed fodder shortage was increased, and it was also ranked as the most severe disaster by $64.1 \%$ of the interviewees. Furthermore, a worse condition for animal health was perceived by $54.2 \%$ of the producers, which was rated as the second most severe disaster. Almost $71.6 \%$ of the farmers recalled the theft rate was almost unchanged. For agro-tourism farmers (Figure 3c), the results indicated that tourist activities and business were all decreased as the weather became more variable than before, which was recalled by $61 \%$ and $69.2 \%$ of the interviewed farmers, respectively. Additionally, tourist activity decrease was ranked as the most severe disaster by $28.9 \%$ of the agro-tourism farmers. However, while a diverse group of farmers provided many examples of how extreme climate can regularly and negatively affect their production, few if any expressed that it strongly influenced the options they chose, such as crop diversification. 


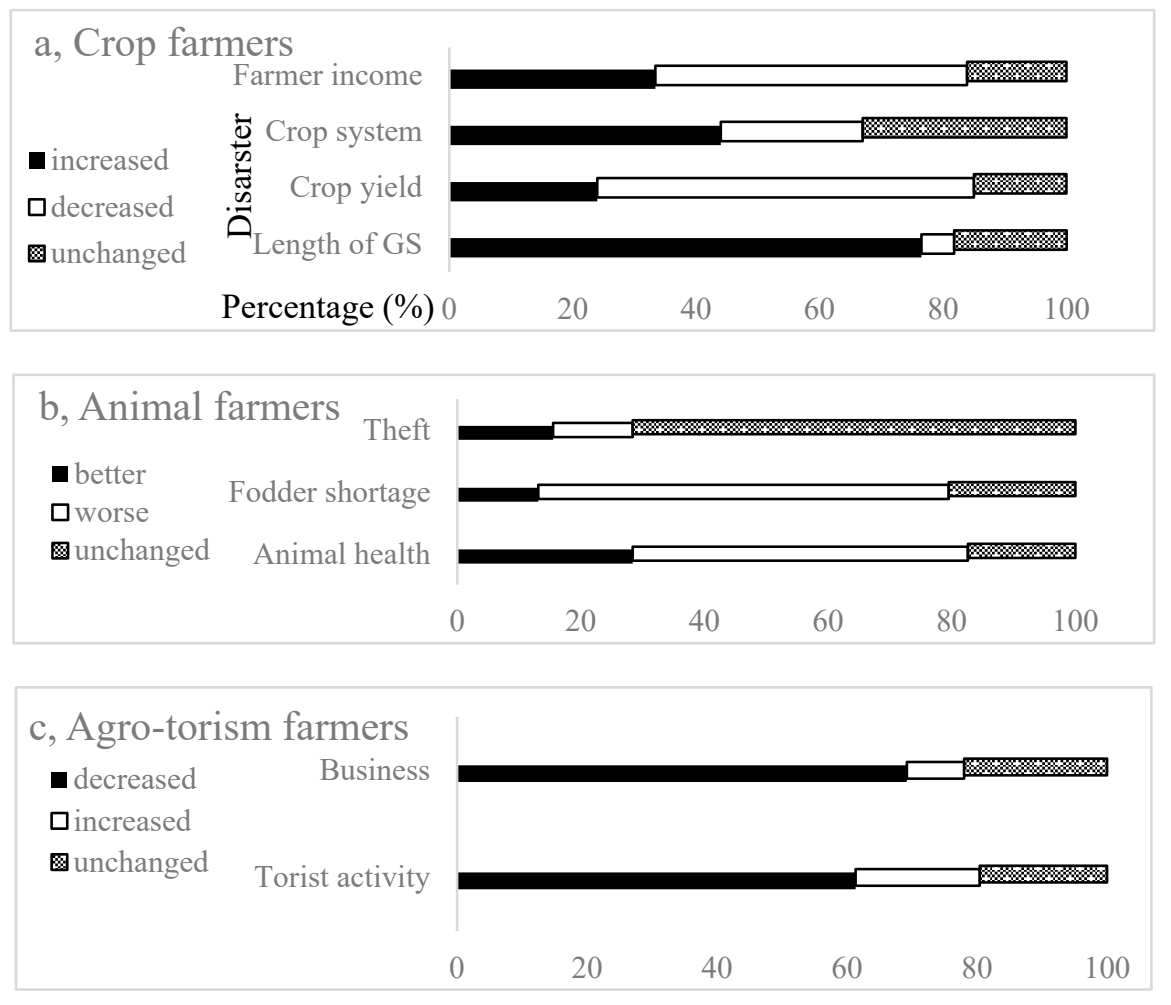

Figure 3. Perception of agricultural disasters among the three different types of farmers in the study area (GS, growing season). (a) Crop farmers; (b) Animal farmers; (c) Agro-torism farmers.

\subsection{Climate Barriers for Adaptation}

As shown in Table 3, all the interviewed producers in the region encountered multiple obstacles to climate adaptation. Our findings showed that the obstacles reported by interviewed producers were positioned first for the institutional category $\left(B_{i}=0.611\right)$. More than $71.8 \%$ of the producers recalled that they did not acquire the needed resources and assets, as well as government incentives, needed to deal with the changing climate. The severity of institutional obstacles was followed by normative barriers with a $B_{i}$ of 0.551 . During the interview, $60.0 \%$ of the farmers stated that they often adopted an inefficient and traditional manner to cope with the changing agricultural context. In addition, they selected delayed remedy measures after climatic agricultural disasters occurred. The value of $B_{i}$ for information and technological barriers was 0.512 , which ranked as the third greatest barrier faced by farmers. As indicated in Table 3,64.4\% of the interviewed producers cannot receive highly timely and accurate weather warning information, and they also have not obtained the technology extension support for crop production, livestock breeding, and business improvement. The perception barriers were the lowest, and the barriers index was 0.460 , but $55.6 \%$ of the interviewees had perceptive barriers in the changing context awareness of drought frequency, new pests, and extreme weather events in the area during the last several years.

More specifically, the statistical comparisons in the multi-independent samples nonparametric tests demonstrated that the institutional, normative, technology and information, and perception obstacles among the three types of farmers were significantly different at a level of $p<0.05$ (Table 3 ). 
Table 3. Barrier index $\left(B_{i}\right)$ for different categories of farmers and the proportion ( $\mathrm{P} \%$ ) of farmers facing barriers in the total surveyed farmers (Bi is the barrier index, which represents the severity of the barriers farmers encountered. P (\%) is the portion of farmers who meet the adaptation obstacles in the total surveyed farmers. Based on the Bi, we can rank the severity of the different barriers, while according to the $\mathrm{P}(\%)$, we can see the rate of the farmers encounter the obstacles in the total interviewed participants).

\begin{tabular}{|c|c|c|c|c|c|c|c|c|c|}
\hline \multirow{2}{*}{ Variable } & \multicolumn{2}{|c|}{ Crop Farmers $(n=85)$} & \multicolumn{2}{|c|}{ Animal Farmers $(n=68)$} & \multicolumn{2}{|c|}{ Agro-Tourism Farmers $(n=81)$} & \multicolumn{2}{|c|}{ All Farmers (n = 234) } & \multirow{2}{*}{$\begin{array}{c}\text { Chi-Square } \\
(p)\end{array}$} \\
\hline & $\mathbf{B i}$ & $P(\%)$ & $\mathbf{B i}$ & $\mathbf{P}(\%)$ & $\mathbf{B i}$ & $\mathbf{P}(\%)$ & $\mathbf{B i}$ & $\mathbf{P}(\%)$ & \\
\hline $\begin{array}{l}\text { Institutional } \\
\text { barriers }\end{array}$ & 0.569 & 65.294 & 0.627 & 73.529 & 0.651 & 77.160 & 0.611 & 71.795 & 8.019 (0.018) \\
\hline $\begin{array}{l}\text { Normative } \\
\text { barriers }\end{array}$ & 0.576 & 64.706 & 0.587 & 66.912 & 0.497 & 49.383 & 0.551 & 60.043 & $11.863(0.003)$ \\
\hline $\begin{array}{l}\text { Information } \\
\text { and } \\
\text { technology } \\
\text { barriers }\end{array}$ & 0.452 & 53.725 & 0.565 & 75.980 & 0.531 & 65.844 & 0.512 & 64.387 & $27.534(0.001)$ \\
\hline $\begin{array}{l}\text { Perception } \\
\text { barriers }\end{array}$ & 0.468 & 55.294 & 0.486 & 63.235 & 0.43 & 49.383 & 0.460 & 55.556 & $6.560(0.038)$ \\
\hline
\end{tabular}




\subsubsection{Institutional Barriers $\left(B_{i}=0.611\right)$}

The guidance and stimulus provided to farmers by the government can enhance their enthusiasm and motivation for climate adaptation. However, in our interviews, Figure 4 shows that in terms of the indicators (access to government incentives and availability of resources) for institutional barriers, $72.7 \%$ of producers faced difficulty with government policy incentives $\left(B_{i}=0.620\right)$. The respondents reported that they were unable to acquire government stimulus to adapt to the changing climate, such as farming and animal husbandry extension services, the provision of subsidies and infrastructure. Among the three different types of farmers, agro-tourism farmers $\left(B_{i}=0.706\right)$ encountered the biggest barriers to getting government policy stimulus followed by animal farmers $\left(B_{i}=0.583\right)$ and crop farmers $\left(B_{i}=0.582\right)$ with rates of $85.2 \%, 66.2 \%$ and $65.9 \%$, respectively. Additionally, nearly $70.9 \%$ $\left(B_{i}=0.602\right)$ of the producers noted that it was not easy to access the available resources offered by the government, and some reported that they simply lack the resources to incorporate climate adaptation in their future work plans. Alternatively, animal farmers $\left(B_{i}=0.673\right)$ had the highest barriers for this indicator followed by agro-tourism farmers $\left(B_{i}=0.599\right)$ and crop farmers $\left(B_{i}=0.557\right)$ with proportions of $85.2 \%, 66.2 \%$, and $65.9 \%$, respectively (Figure 4 ).



Figure 4. The index of different barriers $\left(B_{i}\right)$ faced by different types of farmers to climate change adaptation in the study area.

3.2.2. Normative Barriers $\left(B_{i}=0.551\right)$

We applied manner of adaptation and rationality of adaptation opportunity to represent farmers' normative barriers. In the survey, $62 \%$ of interviewees voiced that they implemented post-disaster temporary remedy adaptation practices (such as idling farmland for crop farmers, selling livestock for animal farmers, and improving roads for agro-tourism farmers) to cope with climate risks $\left(B_{i}=0.561\right)$, and they did not want to take some preventive actions or create pre-disaster responses. The study also found that crop farmers had the greatest barriers $\left(B_{i}=0.601\right)$ to grasping adaptation opportunity rationality followed by animal farmers $\left(B_{i}=0.583\right)$ and agro-tourism farmers $\left(B_{i}=0.503\right)$, and the rates for the three different farmer categories were $64.7 \%, 66.2 \%$, and $49.4 \%$, respectively. Regarding 
the manner of adaptation, $58.1 \%$ of producers responded that they often adopted adaption practices based on traditional or their own subjective farming experience, and they lacked scientific and efficient coping measures $\left(B_{i}=0.541\right)$. Specifically, $50.6 \%$ of the agro-tourism farmers utilized an inefficient manner to incorporate climate change, and the barrier index was 0.503 , while the percentage of crop farmers and animal farmers with this barrier was even higher, at $69.4 \%$ and $67.6 \%$, with $B_{i}$ of 0.551 and 0.591, respectively (Figure 4).

\subsubsection{Information and Technology Barriers $\left(B_{i}=0.512\right)$}

Three indicators were used to reflect gaps in information and technology accessibility, including timeliness, accuracy of information acquisition, and access to technical support. Figure 4 shows that the barriers of acquiring climate information accurately were positioned first $\left(B_{i}=0.528\right.$, and the proportion was $73.9 \%)$ among the three indicators, followed by timeliness of information acquisition $\left(B_{i}=0.515\right.$, and the rate was $70.5 \%)$ and technology support $\left(B_{i}=0.494\right.$, and the percentage was $\left.48.7 \%\right)$. In terms of the accuracy of climate or weather information obtained, the agro-tourism farmers claimed the most $\left(B_{i}=0.566\right)$ that they sometimes obtained inaccurate weather information, which prevented them from enacting a pre-disaster response, followed by animal farmers $\left(B_{i}=0.555\right)$ and crop farmers $\left(B_{i}=0.470\right)$. With respect to timeliness of information acquisition, nearly $77.9 \%$ of the animal farmers, $77.8 \%$ of the agro-tourism farmers and $57.6 \%$ of the crop farmers could not acquire timely weather disaster warning information. In addition, the survey also found that a few producers acquired information through neighborhood communication, which may have more locally relevant information than distant government sources. Regarding technical support, the crop farmers had the lowest barrier index $\left(B_{i}=0.431\right)$, while the barrier index for the agro-tourism farmers and animal farmers was higher, with Bi of 0.478 and 0.591 , respectively. Only $36.5 \%$ of the crop farmers said that they lacked the professional technical knowledge to develop their agricultural production to respond to climate change, while the proportion for agro-tourism and animal farmers was $45.7 \%$ and $67.6 \%$, respectively (Figure 4).

\subsubsection{Perception Barriers $\left(B_{i}=0.460\right)$}

Indicators of perception of drought frequency, new pests, and extreme events in the last several years were selected to characterize perception barriers in this work. Among these three barriers, producers had the largest accuracy in terms of cognition of drought frequency in the last several years $\left(B_{i}=0.355\right.$, and the proportion was $50.4 \%)$, followed by the perception of extreme events $\left(B_{i}=0.403\right.$, and the proportion was $55.6 \%)$, and the lowest accuracy in perception was for new pest populations in the last few years $\left(B_{i}=0.550\right.$, and the proportion was $71.8 \%$ ). In addition, there were large differences among the three categories of producers in their perceptions of the changing climate. Based on the survey results, crop farmers had the highest perception accuracy of drought frequency $\left(B_{i}=0.389\right)$ followed by agro-tourism farmers $\left(B_{i}=0.401\right)$ and animal farmers $\left(B_{i}=0.505\right)$ with proportions of $41.2 \%, 43.2 \%$, and $70.6 \%$, respectively. Judging from perception of extreme weather in the last several years, animal farmers faced the greatest barriers $\left(B_{i}=0.410\right)$, while crop farmers and agro-tourism farmers faced a similar extent of obstacles with barrier indexes of 0.403 and 0.404 , respectively. However, crop farmers encountered the greatest severe barriers for awareness of new pest populations $\left(B_{i}=0.611\right)$ followed by animal farmers $\left(B_{i}=0.544\right)$, and the agro-tourism farmers had the highest cognition accuracy $\left(B_{i}=0.493\right)$. Specifically, $80 \%$ of the crop farmers claimed that with the increased use of pesticides and improved agricultural production techniques, the number of perceived pests has declined significantly in recent years, and the proportion for animal farmers and agro-farmers was even smaller, exhibiting values of $73.5 \%$ and $63.7 \%$, respectively (Figure 4 ).

\subsection{Climate Enablers for Adaptation}

Farmers were also interviewed about their fundamental enablers for adaptation. The findings in Figure 5 shows that the enablers mentioned were positioned first in agricultural subsidies $(62.53 \%)$ followed by farming or advanced breeding techniques $(60.67 \%)$ and credit facilities $(59.84 \%)$. Agricultural insurance was the least important enabler for adaptation to climate change, and $60.29 \%$ of 
farmers remarked that insurance can be too expensive for smallholder producers or low income people, while insurers were often unwilling to cover catastrophic risks, which may demand the introduction of publicly supported insurance. Additionally, there were differences in terms of demand for adaptation to climate change among the three categories of farmers. Crop farmers had the strongest enabler for agricultural subsidies $(72.75 \%)$ followed by disaster warning information $(66.77 \%)$ and farming or breeding techniques (65.21\%) (Figure 5). Some of the crop farmers stated that they urgently need more agricultural subsidies to change crop varieties and compensate the large investments in agriculture, such as fertilizer, irrigation, and greenhouses. Among the animal farmers, housing and electricity infrastructure was the urgent need $(66.79 \%)$, animal epidemic prevention or pest management was the second $(64.60 \%)$, and livestock market information was the third demand (58.79\%). Animal farmers required improved house design and structures, ventilation, and water sprays/misters. For agro-tourism farmers, credit facilities were the prominent enabler (71.03\%) followed by transportation and water conservation infrastructure $(69.88 \%)$ and agriculture subsidies $(66.79 \%)$. The agro-tourism farmers pointed out that credit facility access and borrowing money from rural credit unions or banks will urgently help them to improve the road infrastructure, the overnight accommodation for tourists, and work as tourist guides.



$\rightarrow$ Crop farmers $\rightarrow$-Animal farmers $\rightarrow$-Agro-tourism farmers $\rightarrow$ - All farmers

Figure 5. The proportion (\%) of enablers to adapt to the changing climate among three categories of farmers in the study area.

\section{Discussion}

\subsection{Farmers' Attitudes toward Climate Change}

Knowing how producers recognize the effect of local climate change on agricultural production is essential for developing effective response actions to cope with climate change [11]. According to this study, it was evident that most of the producers (including crop farmers, animal farmers, and agro-tourism farmers) in the region recognized gradual changes in climate change, which was in line with the observed data from the meteorological station (Figure 2), and there was no contradiction 
between different categories of farmers. This perception was in keeping with the findings of other work conducted in China $[19,36]$. In addition, we compared the results we obtained with other research studies. Producers' perceptions on climate change differed greatly across different geographical areas [17]. These observations included decreasing rainfall and increasing temperature in Chile [37], Kenya [38], the Midwestern US [39], and Pakistan [40]. Moreover, farming had been influenced by climate change in a broad variety of ways, which were perceived by different categories of farmers in our research, and very few believed that climate change had no influence on agriculture (Figure 3). Crop farmers perceived that the length of growing season had increased most, animal farmers reported that fodder shortage and animal disease increased most as a result of increasing climate instability, while agro-tourism farmers perceived that tourist activities and business were all decreased because the weather was more changeable than before. The findings of [11] and [41] also reported that climate change will negatively impact farming systems and livelihoods.

\subsection{Factors Influencing Farmers' Adaptation Barriers and Enablers}

The acceleration of the observed effect of climate change drove farmers' adaptations to the changing context, which are currently in the stage of translation into local-scale actions [22]. Nevertheless, climate adaptation can be challenging if producers encounter obstacles that are manifested not only in constraints of external factors but also in the internal obstacles of farmers, as shown in Table 2. The findings showed that the most essential impediment was institutional barriers, which had the highest barrier index value of 0.611. Currently, due to lack of policy incentives and top-down support, farmers are often in a passive state of adaptation, particularly agro-tourism farmers, who had the highest institutional barrier index (Table 3). Furthermore, an existing study indicated that the absence of institutional stimulus may result in individuals performing various practices for climate adaptation, for example, households in the countryside were more apt to recognize climate stress, while less institution stimulus made them less inclined to adapt. In city regions, households were less likely to perceive climate change disaster, but corresponding incentives made them more apt to adopt measures [42]. In the case of agricultural adaptation, institutions may assist farmers to devise adaptation strategies, and adaptation may not occur in an institutional vacuum [29]. Therefore, there is an urgent need for local governments to adopt stimulus actions to incentivize farmers to actively fight against the changing climate.

Normative barriers were the second obstacle to adapt to climate change according to our study $\left(B_{i}\right.$ $=0.551$, Table 3 ). During our field investigation, we observed that most of the young people in the area had gone out to work, and most of the people left to farm were the old people. China's Shaanxi Province (SX) has some of the oldest sites of Chinese civilization and therefore has an equally long history of agricultural activity. Traditional farming experiences are deeply rooted, which may be a restriction factor for local producers' capacity to scientifically regulate and respond to the changing context. Examples included pruning that reduced water demand, mulching under crops to increase humidity in the soil and canopy management to control sun exposure and resulting fruit damage. The authors of $[43,44]$ also reported that the normative assessment formed from agricultural experience and educational level was even a critical driver influencing climate adaptation. In addition, some differences were seen among the specific three groups of farmers, which was reflected in animal farmers who had the highest value of normative barrier index $\left(B_{i}=0.587\right.$, Table 3$)$. Though animal disease epidemiology was extremely sensitive to host community composition, especially population mixing, vaccination is a critical adaptation choice that uses rapid cooling and thermostats to decrease disease infestation and pests where appropriate [45]. However, in the interviews, few animal farmers adopted these measures to address the increased risk of disease epidemiology caused by the changing climate.

The impact of technology on climate adaptation is even more important in developing nations, where food security remains a major part of the population's struggle, and the coming climate change is estimated to cause this to worsen [46]. In the future, deployment and innovation of agricultural technologies will greatly shape how well producers adapt to the changing context. 
However, our survey observed that almost $64.39 \%$ of producers still faced information and technology barriers $\left(B_{i}=0.512\right.$, Table 3$)$. It is notable that there were some producers in the region who used traditional knowledge and their own farming experience to forecast weather instead of relying on weather forecasts, due to the inaccessibility of that information and the disbelief of climate forecasts provided by government agencies. In addition, the survey found that a few producers acquired information through neighborhood and relatives' communication, which may have more locally relevant information than distant government sources. These results were highly consistent with those obtained by Umar [47]. The most commonly employed adaptation technology in the region was the change in farm manure management, growing diverse varieties, and planting and harvesting. However, a few farmers had undertaken adaptation practices such as growing drought tolerant crops and rainwater harvesting. Interviewed producers reported that low use of these measures was because of the lack of technical know-how about new varieties and crops.

Cognitive obstacles were the weakest barriers in our study $\left(B_{i}=0.460\right.$, Table 3$)$, but $55.56 \%$ of the producers still had a perceptive bias regarding the changing climate. Farmers often had more profound memories of climate disasters that had destroyed their production compared with the general temperature and participation change [48]. This was even more evident for crop farmers who had the highest perception of new pest barriers $\left(B_{i}=0.611\right.$, Figure 4$)$ among the three types of farmers. Nevertheless, $55.56 \%$ of participating producers reported that extreme climatic events (frost, flood, and wildfire) and effects had occurred more frequently. In fact, the perceptions of the different typologies of producers on climate issues can be reinforced and derived from their sensory perception and their direct personal climate experience, which were usually associated with damage to farming operations such as increased management, production losses, and input costs [49]. This result was supported by [50]. Those unexpected experiences may result in a sad or desperate sentiment in different categories of producers, which affects their proper cognition of changing climatic stress.

While almost all categories of farmers encountered different barriers to adapt to climate change, different types of producers varied in the effects they experienced, their adoption of adaptation practices, as well as adaptation enablers. Crop farmers recorded the lowest earnings among the three categories of farmers. Most of them intend to improve their activities by purchasing trucks, plastic film, and greenhouses for vegetable cultivation but are restricted by funding; thus, their most important enabler for adaptation was government agricultural subsidies. The highest earnings among the three types of producers were reported among the animal farmers, although there were producers of this type whose earnings were still small. Some animal farmers reported that for animals usually outdoors, housing is an adaptation, and they need additional shelter during times of excessive cold and heat. Therefore, from their own points of view, they urgently needed more government infrastructure improvements such as livestock housing. In terms of agro-tourism operators, their most important enabler was credit facilities, as they reported that tourist activities may be as sensitive to the changing climate as raising livestock and planting crops, given that rainy summers deter tourists. These different enablers and barriers among crop farmers, animal farmers, and agro-tourism operators also reflected the differential vulnerability of the agro-ecosystems and the heterogeneity in climate change effects and producers' responses [51].

\section{Conclusions}

Systematic identification of the obstacles and enablers for climate adaptation is a prerequisite to the successful adoption of climate adaptation strategies, particularly in developing nations with limited resources, technology, and funding. To accomplish these objectives, the barrier index $\left(B_{i}\right)$ was estimated to measure adaptation barriers faced by crop farmers, animal farmers, and agro-tourism operators. Our findings revealed that farmers across three agricultural operation categories were found to encounter various climate adaptation obstacles, of which institutions were the biggest obstacles $\left(B_{i}=0.611\right)$, such as lack of government incentives, inability to obtain resources or assets, followed by normative barriers $\left(B_{i}=0.551\right)$, information and technology barriers $\left(B_{i}=0.512\right)$, and perception 
barriers $\left(B_{i}=0.460\right)$. More specifically, different categories of producers developed numerous methods in which agricultural research centers, relevant institutions, and governments could assist producers to adapt to the changing context. Among the subset of 85 crop farmers, the most frequently mentioned enablers were agricultural subsidies $(72.75 \%)$ and disaster warning information (66.77\%). Housing infrastructure $(66.79 \%)$ and animal epidemic prevention $(64.6 \%)$ were the most frequent enablers for the subset of 61 animal farmers, while the need for credit facilities $(71.03 \%)$ and transportation infrastructure $(69.88 \%)$ was elevated among the subset of 81 agro-tourism operators. The form of these responses was strongly influenced by the economic and policy framework within which producers operated and experienced, demonstrating that in developing economies, there is an important role to be played by policy in enhancing agricultural resilience and working towards broader sustainability goals.

\section{Policy Implications}

One of the largest challenges facing humanity is feeding the nation's population in a nutritious, equitable, and sustainable manner in the context of climate change. Transformational policies that help producers to cope with and eliminate adaptation barriers while also being climate resilient and contributing minimal emissions are urgently required. More specifically, strong effective management is required at various levels, combining top-down (the perspective of policy makers) and bottom-up processes (the perspective of local farmers). Based on the findings obtained in this research, the following policy recommendations are presented. First, given the heterogeneity barriers and enablers of different categories of farmers' experience with changing climate, top-down visions from policy makers will be critical to promote agricultural adaptation strategies that are accessible for farmers and can be tailored to specific climatic experiences and agricultural context. Extensive adaptation provincial guiding programs have been proposed to help producers adapt to climate change in the region. However, many of the actions are resource-intensive and are often beyond the reach of the different categories of producers who have limited information and technology, credit facilities, and capital. Thus, priority and differentiated adaptation practices should be intensified to eliminate adaptation barriers and reach a productive match between adaptation enablers and policy incentives, for example, provide more subsidies and disaster warning information for crop farmers, improve housing infrastructure and spread livestock market information for animal farmers, and increase credit facilities and improve road conditions for agro-tourism operators. Second, in light of the complexity of climate adaptation, bottom-up experiences and visions from local producers who are exposed every day to the tangible impacts of the changing climate on their agricultural activities can play a vital role in assisting with the mitigation of climate effects at the local level. Developing the knowledge base via coordinated research with local producers and through the co-production of scientific knowledge will be essential to decrease the shortage of data and promote the development of targeted adaptation practices in response to local climate stress. More specifically, accommodating the knowledge of local producers and the local environment both in terms of political agenda and research is critical for addressing global climate changes [41].

Author Contributions: Conceptualization, L.M. Formal analysis, L.M. and Y.L. Funding acquisition, L.M. and L.F. Methodology, L.M. Project administration, L.M. and L.F. Software, Y.L. and C.W. Validation, C.W. and Y.L. Writing-original draft preparation, L.M. All authors have read and agreed to be published version of the manuscript.

Funding: This research was funded by the major projects of the humanities and Social Sciences base of the Ministry of Education (17JJD790015); the funded Projects for the Academic Leaders and Academic Backbones, Shaanxi Normal University, China (18QNGG011); the Ministry of Education Humanities and Social Science Research Youth Foundation (17XJC790010); Shaanxi Social Science Fund (2018D29); Key Laboratory Project of Shaanxi Education Department (05JS040).

Conflicts of Interest: The authors declare no conflict of interest. 


\section{References}

1. Popoola, O.O.; Yusuf, S.F.G.; Monde, N. Information sources and constraints to climate change adaptation amongst smallholder farmers in Amathole district municipality, Eastern cape province, South Africa. Sustainability 2020, 12, 5846. [CrossRef]

2. Wahid, U.; Muhammad, N.; Muhammad, K.; Takaaki, N. Assessing farmers' perspective on climate change for effective farm-level adaptation measures in Khyber Pakhtunkhwa, Pakistan. Environ. Monitor. Assess. 2019, 191, 1-18.

3. IPCC Secretariat, 2018. Summary of Policy Makers of IPCC: Special Report on Global Warming of $1.5^{\circ} \mathrm{C}$ Approved by Governments. Geneva, Switzerland, 1-5. Available online: https://www.scirp.org/reference/ ReferencesPapers.aspx?ReferenceID=2521802 (accessed on 9 September 2020).

4. Cadez, S.; Czerny, A. Climate change mitigation strategies in carbon-intensive firms. J. Clean. Prod. 2016, 112, 4132-4143. [CrossRef]

5. Czerny, A.; Letmathe, P. Eco-efficiency: GHG reduction related environmental and economic performance. The case of the companies participating in the EU emissions trading scheme. Bus. Strat. Environ. 2017, 26, 791-806. [CrossRef]

6. Cadez, S.; Czerny, A.; Letmathe, P. Stakeholder pressures and corporate climate change mitigation strategies. Bus. Strat. Environ. 2019, 28, 1-14. [CrossRef]

7. Talbot, D.; Boiral, O. Strategies for climate change and impression management: A case study among Canada's large industrial emitters. J. Bus. Ethics 2015, 132, 329-346. [CrossRef]

8. Cadez, S.; Guilding, C. Examining district carbon cost structures and climate change abatement strategies in $\mathrm{CO}_{2}$ polluting firms. Account. Audit. Account. J. 2017, 30, 1041-1064. [CrossRef]

9. Huang, K.C.; Lee, C.J.; Chan, S.L.; Tai, C.H. Vulnerability assessment and adaptation strategies for the impact of climate change on agricultural land in Southern Taiwan. Sustainability 2020, 12, 4637. [CrossRef]

10. Ghanian, M.; Ghoochani, O.M.; Dehghanpour, M.; Taqipour, M.; Taheri, F.; Cotton, M. Understanding farmers' climate adaptation intention in Iran: A protection motivation extended model. Land Use Policy 2020, 94, 104553. [CrossRef]

11. Khanal, U.; Wilson, C. Derivation of a climate adaptation index and assessing determinants and barriers to adaptation among farming households in Nepal. Environ. Sci. Policy 2019, 101, 156-165. [CrossRef]

12. Ado, A.M.; Jin, L.S.; Savadogo, P.; Li, B.; Shah, A.A. Farmers' awareness and perception of climate change impacts: Case study of Aguie district in Niger. Environ. Dev. Sustain. 2019, 21, 2963-2977. [CrossRef]

13. Altieri, M.A.; Nicholls, C.I. The adaptation and mitigation potential of traditional agriculture in a changing climate. Clim. Chang. 2017, 140, 33-45. [CrossRef]

14. Masud, M.M.; Azam, M.N.; Mohiuddin, M.; Banna, H.; Akhtar, R.; Alam, A.S.A.F.; Begum, H. Adaptation barriers and strategies towards climate change: Challenges in the agricultural sector. J. Clean. Prod. 2017, 156, 698-706. [CrossRef]

15. Fahad, S.; Wang, J. Farmers' risk perception, vulnerability, and adaptation to climate change in rural Pakistan. Land Use Policy 2018, 79, 301-309. [CrossRef]

16. Asseng, S.; Pannell, D.J. Adapting dryland agriculture to climate change: Farming implications and research and development needs in Western Australia. Clim. Chang. 2013, 118, 167-181. [CrossRef]

17. Agrawala, S. Adapting to climate change: Costs, benefits, and modelling approaches. Int. Rev. Environ. Resour. Econ. 2011, 5, 245-284. [CrossRef]

18. Kibue, G.W.; Liu, X.; Zheng, J.; Zhang, X.; Pan, G.; Li, L.; Han, X. Farmers' perception of climate change and factors influencing adaptation: Evidence from Anhui and Jiangsu, China. Environ. Manag. 2016, 57, $976-986$. [CrossRef]

19. Shi, X.; Sun, L.; Chen, X. Farmers' perceived efficacy of adaptive behaviors to climate change in the Loess Platear, China. Sci. Total. Environ. 2019, 697, 134217-134226. [CrossRef]

20. Jones, L.; Boyd, E. Exploring social barriers to adaptation: Insights from western Nepal. Glob. Environ. Chang. 2011, 21, 1262-1274. [CrossRef]

21. Below, T.B.; Mutabazi, K.D.; Kirschke, D.; Franke, C.; Sieber, S.; Siebert, R.; Tscherning, K. Can farmers' adaptation to climate change be explained by socio-economic household-level variables? Glob. Environ. Chang. 2012, 22, 223-225. [CrossRef] 
22. Simonet, G.; Leseur, A. Barriers and drivers to adaptation to climate change- a field study of ten French local authorities. Clim. Chang. 2019, 155, 621-637. [CrossRef]

23. Moser, S.; Ekstrom, J.A. A framework to diagnose barriers to climate change adaptation. Proc. Natl. Acad. Sci. USA 2010, 107, 22026-22031. [CrossRef] [PubMed]

24. Whitney, C.K.; Ban, N.C. Barriers and opportunities for social-ecological adaptation to climate change in Coastal British Columbia. Ocean. Coas. Manag. 2019, 179, 104808. [CrossRef]

25. Gifford, R.; Kormos, C.; Mclntyre, A. Behavioral dimensions of climate change: Drivers, responses, barriers, and interventions. Clim. Chang. 2011, 2, 801-827. [CrossRef]

26. Vignola, R.; Harvey, C.A.; Bautista-Solis, P.; Avelino, J.; Rapidel, B.; Donatti, C.; Martinez, R. Ecosystem-based adaptation for smallholder farmers: Definitions, opportunities and constraints. Agric. Ecosyst. Environ. 2014, 211, 126-132. [CrossRef]

27. United Nations. Transforming Our World: The 2030 Agenda for Sustainable Development. 2015. Available online: http://www.naturalcapital.vn/wp-content/uploads/2017/02/UNDP-Viet-Nam.pdf (accessed on 25 September 2015).

28. Luo, Y.; Gao, X.J.; Xu, Y.; Zhao, Z.C. Projections of climate change and water resources in Northwest China in the 21st century. In Proceedings of the 25th National Congress and Annual Conference of Chinese Meteorological Society, Beijing, China, 5-7 October 2002.

29. Agrawal, A.; Perrin, N. Climate Adaptation, Local Institutions and Rural Livelihoods; Cambridge University Press: Cambridge, UK, 2009.

30. Boyd, E.; Cornforth, R.J.; Lamb, P.J.; Tarhule, A.; Lélé, M.I.; Brouder, A. Building resilience to face recurring environmental crisis in African Sahel. Nat. Clim. Chang. 2013, 3, 631-637. [CrossRef]

31. Adger, W.N.; Barnett, J.; Brown, K. Cultural dimensions of climate change impacts and adaptation. Nat. Clim. Chang. 2013, 3, 112-117. [CrossRef]

32. Wang, W.J.; Zhao, X.Y.; Cao, J.J.; Zhang, Q. Barriers and enablers to climate change adaptation of mountainous rural communities in developing countries: The case of the eastern Qinghai-Tibetan Plateau of China. Land Use Policy 2020, 95, 104354. [CrossRef]

33. Yang, W.; Xu, K.; Lian, J. Integrated flood vulnerability assessment approach based on TOPSIS and Shannon entropy methods. Ecol. Indict. 2018, 89, 269-280. [CrossRef]

34. Gupta, H. Assessing organizations performance on the basis of GHRM practices using BWM and Fuzzy TOPSIS. J. Environ. Manag. 2018, 226, 201-216. [CrossRef]

35. Khagram, S.; Clark, W.; Raad, D.F. From the environment and human security to sustainable security and development. J. Hum. Dev. 2003, 4, 289-313. [CrossRef]

36. Zhai, S.Y.; Song, G.X.; Qin, Y.C.; Ye, X.Y.; Leipnik, M. Climate change and Chinese farmers: Perceptions and determinants of adaptive strategies. J. Integr. Agric. 2018, 17, 949-963. [CrossRef]

37. Roco, L.; Engler, A.; Bravo-Ureta, B.E.; Jara-Rojas, R. Farmers' perception of climate change in Mediterranean Chile. Reg. Environ. Chang. 2015, 15, 867-879. [CrossRef]

38. Muita, R.R.; Van Ogtrop, F.; Ampt, P.; Vervoort, R.W. Managing the water cycle in Kenyan small-scale maize farming systems: Part 1. Farmer perceptions of drought and climate change. Wiley Interdiscip. Rev. Water 2016, 3, 105-125. [CrossRef]

39. Mase, A.S.; Gramig, B.M.; Prokopy, L.S. Climate change beliefs, risk perceptions, and adaptation behavior among Midwestern US crop farmers. Clim. Risk. Manag. 2017, 15, 8-17. [CrossRef]

40. Abid, M.; Scheffran, J.; Schneider, U.A.; Elahi, E. Farmer perceptions of climate change, observed trends and adaptation of agriculture in Pakistan. Environ. Manag. 2019, 63, 110-123. [CrossRef] [PubMed]

41. Altea, L. Perceptions of climate change and its impacts: A comparison between farmers and institutions in the Amazonas Region of Peru. Clim. Dev. 2020, 12, 134-146. [CrossRef]

42. Bohensky, E.; Smajgl, A.; Brewer, T.D. Patterns in household-level engagement with climate change in Indonesia. Nat. Clim. Chang. 2012, 3, 348-351. [CrossRef]

43. Pasquini, L.; Cowling, R.M.; Ziervogel, G. Facing the heat: Barriers to mainstreaming climate change adaptation in local government in the Western Cape Province, South Africa. Habitat Int. 2013, 40, 225-232. [CrossRef]

44. Li, S.; Juhász-Horváth, L.; Harrison, P.A. Relating farmer's perceptions of climate change risk to adaptation behavior in Hungary. J. Environ. Manag. 2017, 185, 21-30. [CrossRef] 
45. Wreford, A.; Topp, C.F.E. Impacts of climate change on livestock and possible adaptations: A case study of the United Kingdom. Agric. Syst. 2020, 178, 102737. [CrossRef]

46. Chhetri, N.; Chaudhary, P.; Tiwari, P.R.; Yadaw, R.B. Institutional and technological innovation: Understanding agricultural adaptation to climate change in Nepal. Appl. Geogr. 2012, 33, 142-150. [CrossRef]

47. Umar, S. Awareness, manifestation and information sources on climate change among irrigation farmers in Katsina State, Nigeria. Sch. J. Agric. Vet. Sci. 2016, 3, 37-41.

48. Fosu-Mensah, B.Y.; Vlek, P.L.G.; Maccarthy, D.S. Farmers' perception and adaptation to climate change: A case study of Sekyedumase district in Ghana. Environ. Dev. Sustain. 2012, 14, 495-505. [CrossRef]

49. Nguyen, T.P.L.; Seddaiu, G.; Virdis, S.G.P.; Tidore, C.; Pasqui, M.; Roggero, P.P. Perceiving to learn or learing to perceive? Understanding farmers' perceptions and adaptation to climate uncertainties. Agric. Syst. 2016, 143, 205-216. [CrossRef]

50. Islam, M.M.; Barnes, A.; Toma, L. An investigation into climate change skepticism among farmers. J. Environ. Psychol. 2013, 34, 137-150. [CrossRef]

51. Harvey, C.A.; Rodríguez, M.S.; Rodríguez, M.R.M.; Viguera, B.; Guadarrama, A.C.; Vignola, R.; Alpizar, F. Climate change impacts and adaptation among smallholder farmers in Central America. Agric. Food Secur. 2018, 7, 57. [CrossRef]

(C) 2020 by the authors. Licensee MDPI, Basel, Switzerland. This article is an open access article distributed under the terms and conditions of the Creative Commons Attribution (CC BY) license (http://creativecommons.org/licenses/by/4.0/). 